\title{
Current Status of "Watch-and-Wait" Rectal Cancer Treatment in Asia-Pacific Countries
}

\author{
Jung Wook Huh ${ }^{1, \star}$, Kotaro Maeda ${ }^{2, *}$, Zheng Liu $^{3}$, Xishan Wang ${ }^{3}$, April Camilla Roslani ${ }^{4}$, Woo Yong Lee ${ }^{1}$ \\ ${ }^{1}$ Department of Surgery, Samsung Medical Center, Sungkyunkwan University School of Medicine, Seoul, Korea; ${ }^{2}$ Deparment of Surgery, \\ International Center, Fujita Health University Hospital, Toyoake, Japan; ${ }^{3}$ Department of Colorectal Surgery, National Cancer Center, National \\ Clinical Research Center for Cancer, Cancer Hospital, Chinese Academy of Medical Sciences and Peking Union Medical College, Beijing, \\ China; ${ }^{4}$ Department of Surgery, Faculty of Medicine, University of Malaya, Kuala Lumpur, Malaysia
}

Purpose: Current acceptance of the watch-and-wait (W\&W) approach by surgeons in Asia-Pacific countries is unknown. An international survey was performed to determine status of the W\&W approach on behalf of the Asia-Pacific Federation of Coloproctology (APFCP).

Methods: Surgeons in the APFCP completed an Institutional Review Board-approved anonymous e-survey and/or printed letters (for China) containing 19 questions regarding nonsurgical close observation in patients who achieved clinical complete response (cCR) to neoadjuvant chemoradiotherapy (nCRT).

Results: Of the 417 responses, $80.8 \%(\mathrm{n}=337)$ supported the $\mathrm{W} \& \mathrm{~W}$ approach and $65.5 \%(\mathrm{n}=273)$ treated patients who achieved cCR after nCRT. Importantly, $78 \%$ of participants $(n=326)$ preferred a selective W\&W approach in patients with old age and medical comorbidities who achieved cCR. In regard to restaging methods after nCRT, the majority of respondents based their decision to use W\&W on a combination of magnetic resonance imaging results $(94.5 \%, \mathrm{n}=394)$ with other test results. For interval between nCRT completion and tumor response assessment, most participants used 8 weeks ( $\mathrm{n}=154,36.9 \%)$, followed by 6 weeks $(\mathrm{n}=127,30.5 \%)$ and 4 weeks $(\mathrm{n}=102,24.5 \%)$. In response to the question of how often responders followed-up after W\&W, the predominant period was every 3 months (209 participants, 50.1\%) followed by every 2 months (75 participants, 18.0\%). If local regrowth was found during follow-up, most participants (79.9\%, $\mathrm{n}=333$ ) recommended radical surgery as an initial management.

Conclusion: The W\&W approach is supported by $80 \%$ of Asia-Pacific surgeons and is practiced at $65 \%$, although heterogeneous hospital or society protocols are also observed. These results inform oncologists of future clinical study participation.

\section{Keywords: Rectal neoplasms; Neoadjuvant chemoradiotherapy; Watch and wait}

Received: 16 December 2019 • Accepted: 19 January 2020

Correspondence to: Woo Yong Lee, M.D.

Department of Surgery, Samsung Medical Center, Sungkyunkwan University School of Medicine, 81 Irwon-ro, Gangnam-gu, Seoul 06351, Korea Tel: +82-2-3410-0261, Fax: +82-2-3410-6980, E-mail: Iwy555@skku.edu ORCID: https://orcid.org/0000-0002-9558-9019

Co-correspondence to: April Camilla Roslani, MBBCh, MS Department of Surgery, Faculty of Medicine, University of Malaya, 50603 Kuala Lumpur, W. Persekutuan Kuala Lumpur, Malaysia

Tel: +603-7949-2077, Fax: +603-7967-8841, E-mail: aprilroslani@um.edu.my *Jung Wook Huh and Kotaro Maeda contributed equally as co-first authors.

(C) 2020 The Korean Society of Coloproctology

This is an open-access article distributed under the terms of the Creative Commons Attribution NonCommercial License (https://creativecommons.org/licenses/by-nc/4.0) which permits unrestricted noncommercial use, distribution, and reproduction in any medium, provided the original work is properly cited.

\section{INTRODUCTION}

The standard management for patients with locally advanced rectal cancer is neoadjuvant chemoradiotherapy (nCRT) followed by total mesorectal excision, which can produce good local control and long-term survival $[1,2]$. However, radical surgical resection can be associated with postoperative morbidities, including sexual, urinary, and sphincteric dysfunction, in addition to permanent stoma formation [3, 4]. A watch-and-wait (W\&W) approach for select patients with rectal cancer may also allow for the achievement of a complete clinical response (cCR) to CRT [5-7].

Evidence supporting this organ-preserving $\mathrm{W} \& \mathrm{~W}$ paradigm has been recently reported; however, a lack of evidence from randomized clinical trials may be a hurdle for the adoption of this 
approach in routine clinical practice.

Current attitudes toward W\&W among colorectal surgeons in Asia-Pacific countries are unknown. An international survey was performed to determine the current status of $\mathrm{W} \& \mathrm{~W}$ paradigm use on behalf of the Asia-Pacific Federation of Coloproctology (APFCP).

\section{METHODS}

This study was approved by the Samsung Medical Center Institutional Review Board (IRB No. 2019-08-036-001). We designed an online survey using a google survey (https://forms.gle/zuFtVjATomWz4oim9) (Appendix). The survey consisted of 19 questions pertaining to respondent characteristics, general recognition of the W\&W policy, detailed methods for CRT, and follow-up after W\&W. The survey was sent anonymously to APFCP members (except for those in China) from August 31, 2019 to November 16, 2019. Printed letters were sent to the participants in China (mostly Beijing area). The IBM SPSS Statistics ver. 25.0 (IBM Co., Armonk, NY, USA) was used for descriptive statistical analysis. Comparison between groups was tested using the chi-square or Fisher exact test as appropriate. A P-value $\leq 0.05$ was considered statistically significant.

\section{RESULTS}

A total of 417 participants (13.3\%) responded to the survey that was sent to a total of 3,125 email or mail addresses within 3 months from initial contact. Distribution of the responders according to participating country, age, specialty, and affiliation are listed in Table 1. Twenty-three responders (5.5\%) were from Australia, 79 (18.9\%) from Japan, 81 (19.4\%) from Korea, 202 (48.4\%) from China, and the remaining responders were from Bangladesh, England, India, Malaysia, Myanmar, New Zealand, Philippines, Singapore, Thailand, and Vietnam. The majority of responders (407 responders, 97.6\%) were colorectal surgeons, and 379 responders (90.9\%) were staff of a university or tertiary hospital.

\section{General recognition}

Of the 417 responders, $80.8 \%(n=337)$ supported the W\&W approach, and $65.5 \%(\mathrm{n}=273)$ practiced this approach in patients with cCR after nCRT (Fig. 1). Seventy-eight percent of surgeons $(\mathrm{n}=323)$ explained the $\mathrm{W} \& \mathrm{~W}$ option to patients showing $\mathrm{cCR}$ after nCRT. Importantly, $78 \%$ of responders $(n=326)$ preferred a selective $\mathrm{W} \& \mathrm{~W}$ approach in patients with old age and medical comorbidities who achieved cCR, whereas $13 \%(n=54)$ performed radical surgery regardless of clinical response, and 9\% (n =37) always recommended $\mathrm{W} \& W$.

Responders were able to select multiple responses to questions \# 5 and \#7; thus, percentages do not sum to $100 \%$. Lack of experience with this policy $(\mathrm{n}=144,34.5 \%)$ was mainly due to inaccuracy of current evaluation methods $(n=93)$, followed by lack of
Table 1. General characteristics $(\mathrm{N}=417)$

\begin{tabular}{|c|c|}
\hline Characteristic & No. $(\%)$ \\
\hline \multicolumn{2}{|l|}{ Participating country $(n=14)$} \\
\hline Australia & $23(5.5)$ \\
\hline Bangladesh & $1(0.2)$ \\
\hline China & $202(48.4)$ \\
\hline England & $1(0.2)$ \\
\hline India & $4(1.0)$ \\
\hline Japan & $79(18.9)$ \\
\hline Korea & $81(19.4)$ \\
\hline Malaysia & $9(2.2)$ \\
\hline Myanmar & $1(0.2)$ \\
\hline New Zealand & $2(0.5)$ \\
\hline Philippines & $7(1.7)$ \\
\hline Singapore & $2(0.5)$ \\
\hline Thailand & $2(0.5)$ \\
\hline Vietnam & $1(0.2)$ \\
\hline Not available & $2(0.5)$ \\
\hline \multicolumn{2}{|l|}{ Age (yr) } \\
\hline $30-39$ & $90(21.6)$ \\
\hline $40-49$ & $179(42.9)$ \\
\hline $50-59$ & $114(27.3)$ \\
\hline $60-69$ & $33(7.9)$ \\
\hline $70-71$ & $1(0.2)$ \\
\hline \multicolumn{2}{|l|}{ Colorectal surgeon } \\
\hline Yes & 407 (97.6) \\
\hline No & $10(2.4)$ \\
\hline \multicolumn{2}{|l|}{ Affiliation } \\
\hline University or tertiary hospital & $379(90.9)$ \\
\hline Others & $38(9.1)$ \\
\hline \multicolumn{2}{|c|}{ Department of Radiation Oncology } \\
\hline Yes & $370(88.7)$ \\
\hline No & $47(11.3)$ \\
\hline
\end{tabular}

evidence supporting $\mathrm{W} \& \mathrm{~W}(\mathrm{n}=87)$, personal memory of treatment failure $(n=17)$, legal issues $(n=17)$, failure of patient informed consent $(n=7)$, and lack of a radiation facility $(n=5)$. However, 69\% of participants (71 of 103) who had not recommended W\&W were willing to do so in the near future (Fig. 1).

\section{Methods for CRT}

In regard to restaging methods after nCRT, the majority based their decision to use W\&W on a combination of magnetic resonance imaging (MRI) $(94.5 \%, \mathrm{n}=394)$, sigmoidoscopy with biopsy $(70.3 \%, \mathrm{n}=293)$, computed tomography $(\mathrm{CT})(57.8 \%, \mathrm{n}=$ 


\section{Coloproctology $\quad \begin{array}{ll}\text { Annals of Wook Huh, et al. }\end{array}$}

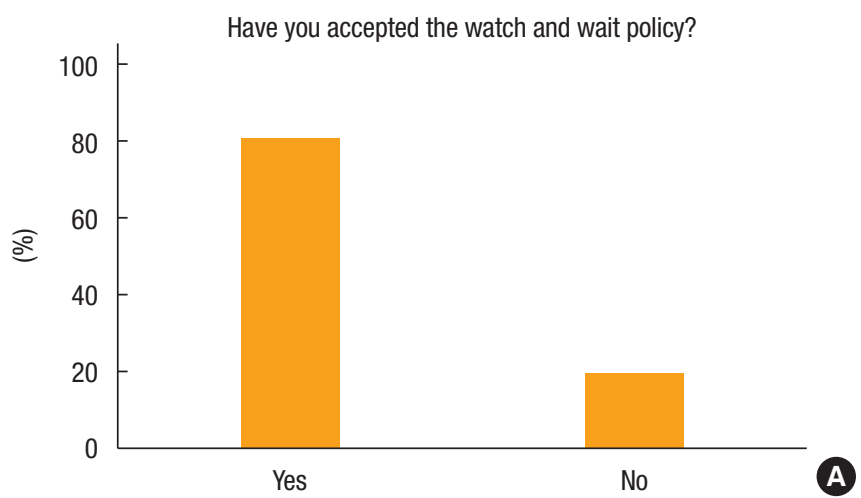

Have you explained the watch and wait option to your patients

if the patients who have received chemoradiotherapy (CRT) have a clinical complete response (CR)?

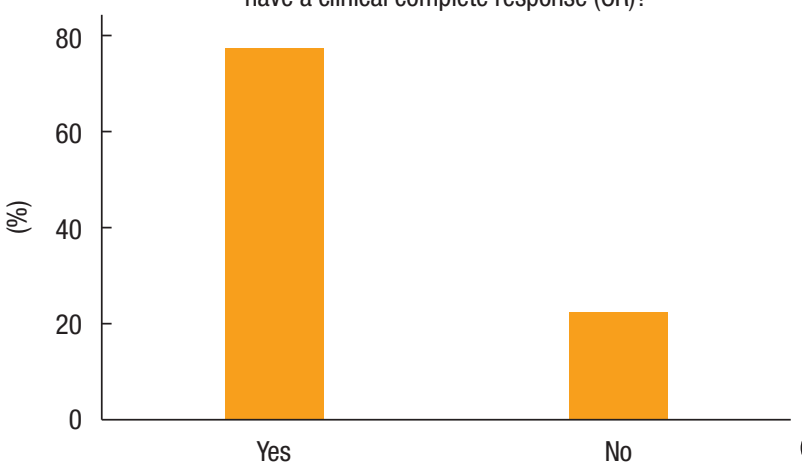

(If you select 'No' in Question 2) Why do you not perform watch and wait policy in clinical practice? (check all)

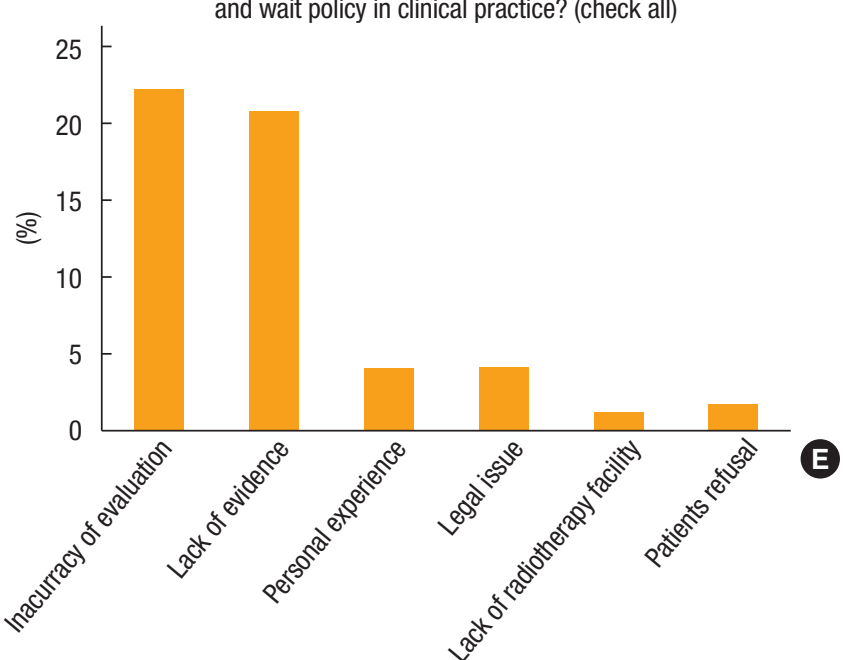

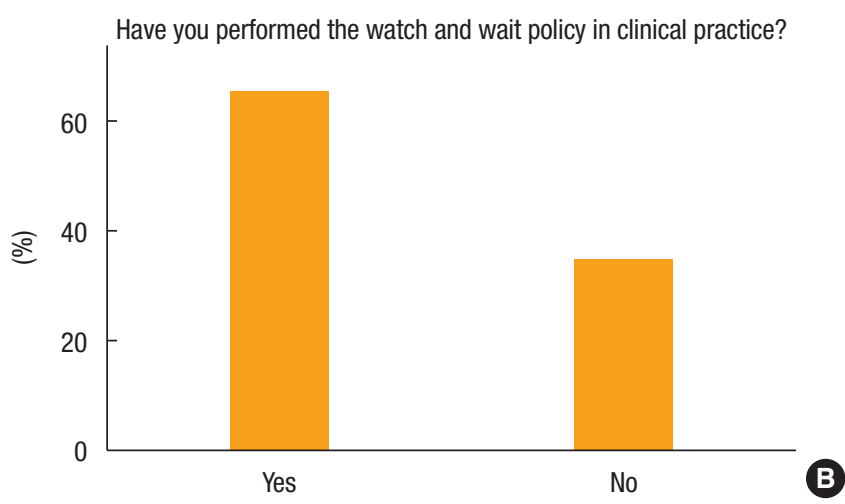

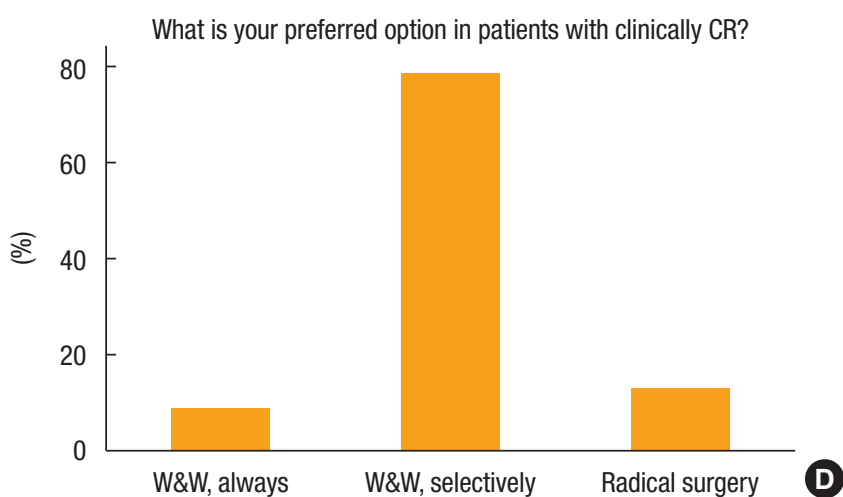

(If you select 'No' in Question 2) Do you plan to perform watch and wait policy in future?

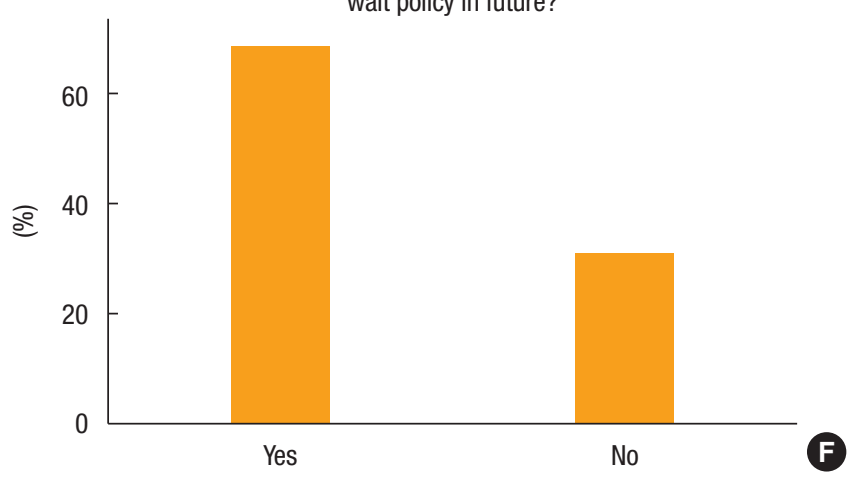

Fig. 1. Questions regarding general recognition for the watch-and-wait (W\&W) policy: (A) acceptance of W\&W, (B) experience with W\&W, (C) choice in patients with clinical complete response (cCR), (D) option for CCR, (E) reasons for not performing W\&W, and (F) future plans for W\&W.

241), positron emission tomography (PET)-CT $(27.3 \%, \mathrm{n}=114)$, endo-rectal ultrasound $(9.1 \%, \mathrm{n}=38)$, and digital rectal examination $(4.6 \%, \mathrm{n}=19)$ (Fig. 2). The predominant combination reported in this study was CT and/or PET and MRI with sigmoid- oscopy and biopsy (213 responders, 51.1\%), followed by CT and/ or MRI (109 responders, 26.1\%), CT and/or MRI with sigmoidoscopy and biopsy (77 responders, 18.5\%), CT and/or PET-CT and MRI (14 responders, 3.4\%), and sigmoidoscopy only (4 re- 


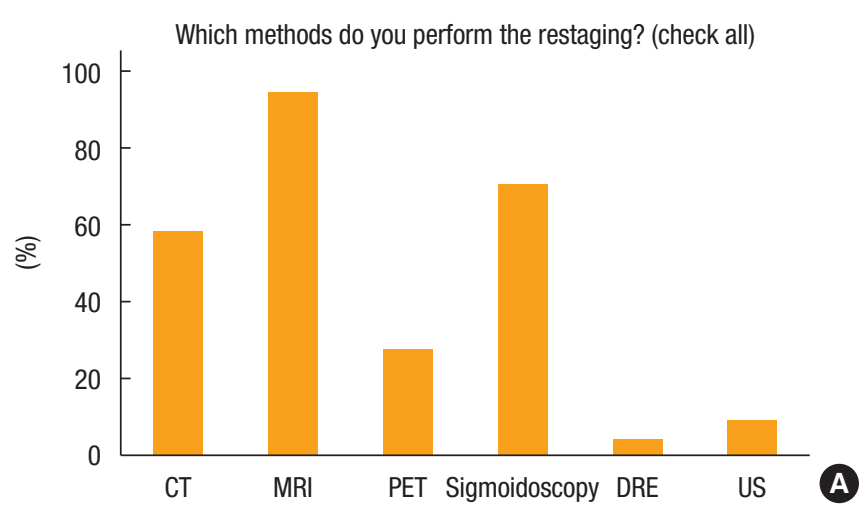

Which chemotherapy regimen do you perform mostly?

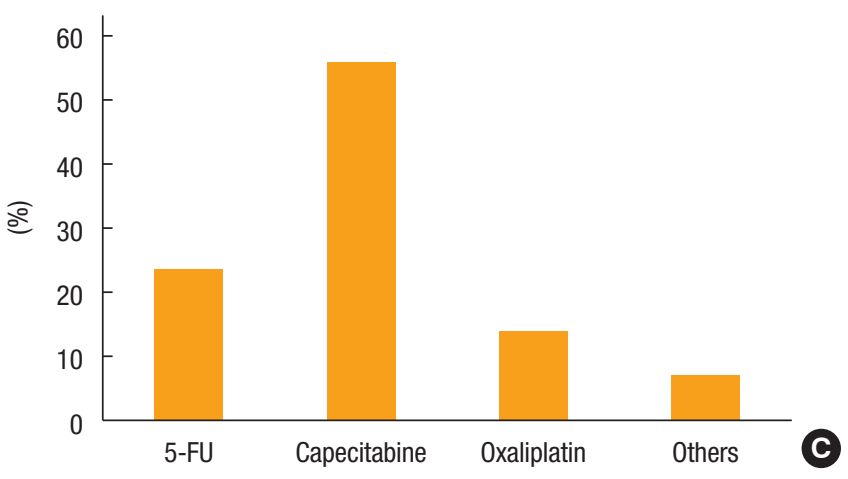

If you do (If you select 'Yes' in Question 10), which regimen do you perform?

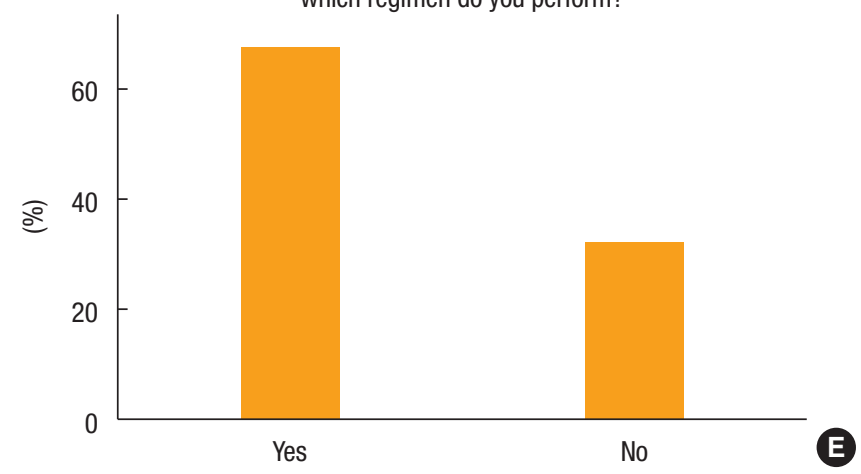

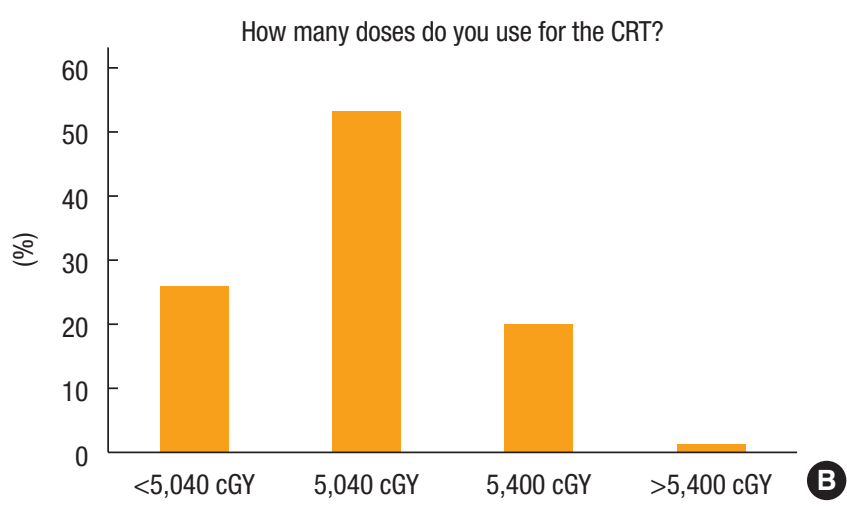

Do you use the chemotherapy in the resting period (the period between completion of CRT and the operation)?

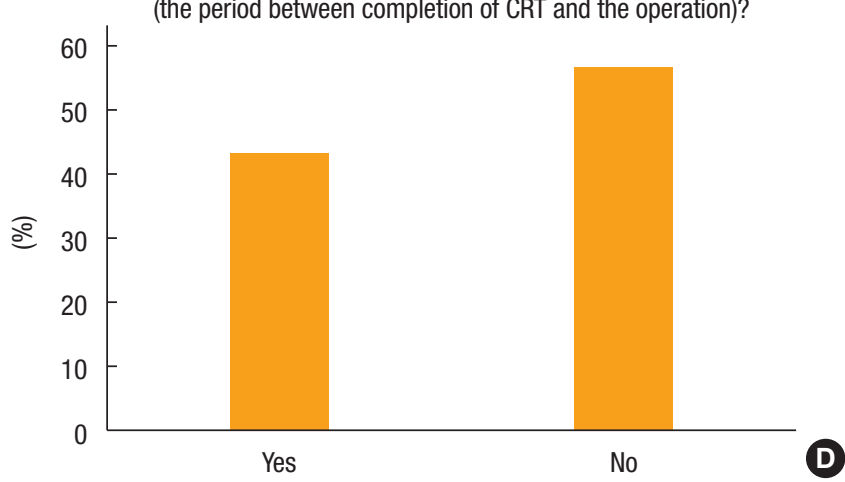

When do you evaluate the CRT response after finishing the CRT?

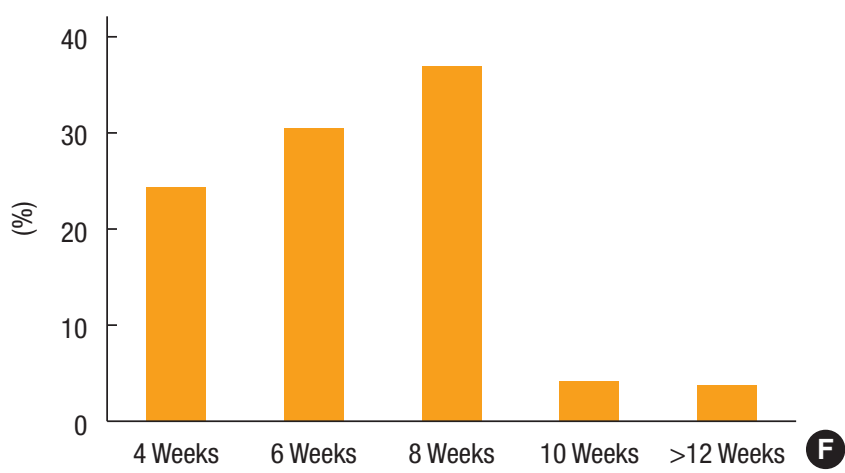

Fig. 2. Methods for chemoradiotherapy: (A) restaging method, (B) radiation dose, (C) chemotherapy regimen, (D) chemotherapy during resting period, (E) chemotherapy regimen during resting period, and (F) evaluation time. CT, computed tomography; MRI, magnetic resonance imaging; PET, positron emission tomography; DRE, digital rectal examination; US, ultrasound; CRT, chemoradiotherapy; 5-FU, 5-fluorouracil.

sponders, $1 \%)$.

Of all respondents, 53.2\% (222 people) preferred a radiation dose of 5,040 cGy and 55.6\% (232 people) favored capecitabine as a chemotherapy regimen. In addition, $43.4 \%(n=181)$ maintained chemotherapy during the resting period, and 67.9\% (127 of 187) repeated the same chemotherapeutic regimen if indicated. For interval between nCRT completion and tumor response assessment, most participants used 8 weeks $(n=154,36.9 \%)$, fol- lowed by 6 weeks $(n=127,30.5 \%)$, and 4 weeks $(n=102,24.5 \%)$ (Fig. 2).

\section{Follow-up after W\&W}

In response to the question of how often the responders followedup after W\&W, the predominant period was every 3 months (209 responders, $50.1 \%$ ), followed by every 2 months (75 responders, $18.0 \%$ ) and every month (74 responders, 17.7\%) (Fig. 3). If local 
After you perform a watch and wait, how often do you follow-up?

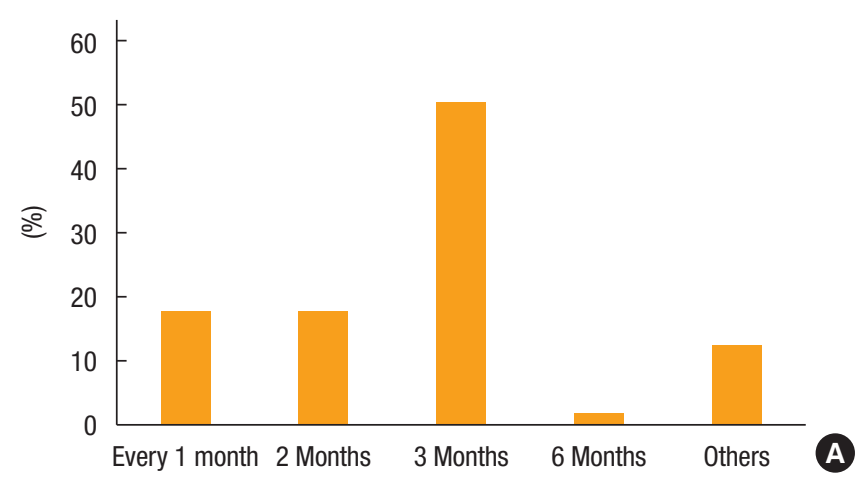

If you find a local regrowth in the patients who did a watch and

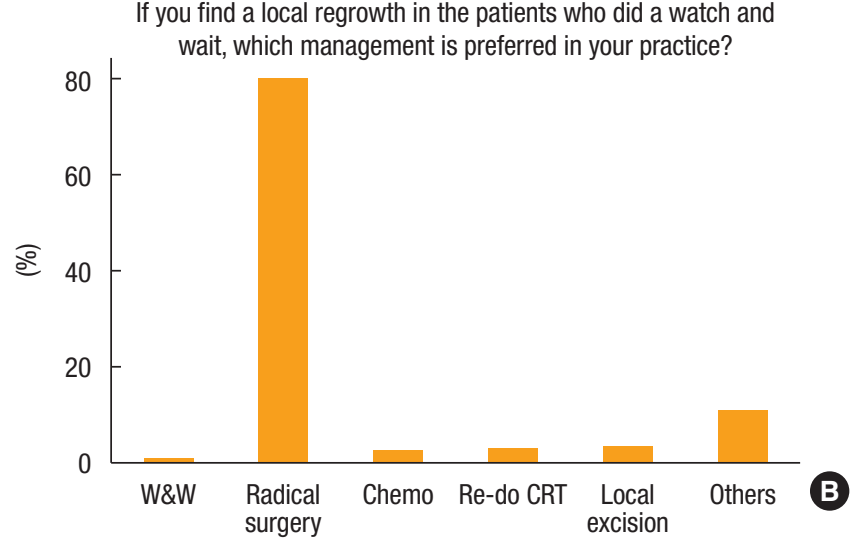

Fig. 3. Follow-up after W\&W: (A) follow-up interval and (B) treatment for local regrowth. CRT, chemoradiotherapy.

regrowth was found during follow-up, most responders $(79.9 \%$, $\mathrm{n}=333$ ) recommended radical surgery as an initial management (Fig. 3).

\section{Comparison between countries}

Current adoption of the W\&W approach between countries is compared in Table 2. Age, affiliation, acceptance of W\&W, experience in clinical practice, informed consent in the case of cCR, reasons for refusal, future plans, restaging methods, radiation dose, chemotherapy regimen, interval between nCRT and evaluation, regular follow-up periods, and management of local regrowth were significantly different between countries. Participants in China favored the W\&W policy in clinical practice compared to all other countries. The preferred treatment option for local regrowth was radical surgery by most surgeons from South Korea.

\section{DISCUSSION}

Management of rectal cancer has evolved substantially over the past 2 decades. Neoadjuvant CRT followed by radical surgery remains the gold standard for locally advanced rectal cancer but is potentially associated with perioperative morbidity and mortality, sexual and urinary dysfunction, and bowel dysfunction as well as risk of permanent stoma $[3,4,8]$. The organ-preserving strategies including close observation following cCR to nCRT have gained attention and are supported by growing evidence $[6,7,9,10]$. In 2014, Habr-Gama et al. [7] reported that $31 \%$ of patients experienced local regrowth by 60 months, of whom $93 \%$ were amenable to salvage (90 of 183 patients). They reported 5-year cancer-specific overall survival and disease-free survival of $91 \%$ and $68 \%$, respectively. Appelt et al. [6] demonstrated that $75 \%$ of patients achieved cCR, and $15 \%$ showed regrowth at 1 year after highdose CRT for 6 weeks (60 Gy in 30 fractions) in 2015. Of note, all patients were salvageable with overall survival and disease-free survival at 2 years. In 2016, the OnCoRe project compared sur- vival between $\mathrm{CCR}$ and $\mathrm{W} \& \mathrm{~W}(\mathrm{n}=109)$ and surgical resection ( $\mathrm{n}$ = 109) after CRT in a propensity-score matched cohort [10]. Local regrowth rate was $34 \%$ with a median of 33 months follow-up; $88 \%$ of patients with nonmetastatic local regrowth were salvageable. That study found no differences in 3-year nonregrowth disease-free survival and 3-year overall survival between the 2 groups. In addition, colostomy-free survival was better in the observational group (74\% vs. $47 \%$ ).

Despite such findings, use of the W\&W protocol is undefined and uncertain. Currently, no universal guidelines on findings or methods that accurately predict cCR following nCRT are established. In addition, no randomized control trials evaluating close observation after CRT are available, probably due to logistical obstacles. Most of the published data available on W\&W are from retrospective analyses with heterogeneous populations, highlighting the importance of our international survey of surgical oncologists. Habr-Gama et al. [11] performed a national survey in Brazil regarding rectal cancer management in 2011. They reported that the W\&W approach in patients with cCR after nCRT was preferred by almost one-third of all participants, and surgeons showed a more favorable opinion than medical oncologists (44.7\% vs. $14.2 \%$ ). In 2010, a national survey in Great Britain and Ireland showed that $58 \%$ of surgeons would never consider W\&W in patients with cCR, and $69 \%$ of participants would not discuss the option of nonoperative management in rectal cancer patients [12]. The 2019 UK National Institute for Health and Care Excellence guidelines recommend W\&W in patients who achieved cCR after nCRT in view of a clinical trial or national registry [13]. In 2018, the American Society of Colon and Rectal Surgeons (ASCRS) conducted an international survey for global practices of W\&W with members of American, European, Australian/New Zealand, and Brazilian colorectal societies [14]. They reported that $41 \%$ of ASCRS respondents trusted the W\&W paradigm compared to $75 \%$ of non-ASCRS respondents. They also concluded that W\&W seemed to be widely practiced throughout the world, despite the lack of a standard protocol in most institutions 
Table 2. Comparison according to country

\begin{tabular}{|c|c|c|c|c|c|}
\hline Variable & China & Japan & Korea & Others & P-value \\
\hline Age (yr) & & & & & $<0.001$ \\
\hline $30-39$ & $63(31.2)$ & $0(0)$ & $19(23.5)$ & $8(14.5)$ & \\
\hline $50-59$ & $37(18.3)$ & $40(50.6)$ & $21(25.9)$ & $16(29.1)$ & \\
\hline $60-69$ & $4(2.0)$ & $13(16.5)$ & $8(9.9)$ & $8(14.5)$ & \\
\hline $70-71$ & $0(0)$ & $0(0)$ & $0(0)$ & $1(1.8)$ & \\
\hline Yes & $195(96.5)$ & $79(100)$ & $81(100)$ & $52(94.5)$ & \\
\hline No & $7(3.5)$ & $0(0)$ & $0(0)$ & $3(5.5)$ & \\
\hline Affiliation & & & & & 0.046 \\
\hline University or tertiary hospital & $189(93.6)$ & $70(88.6)$ & $75(92.6)$ & $45(81.8)$ & \\
\hline Others & $13(6.4)$ & $9(11.4)$ & $6(7.4)$ & $10(18.2)$ & \\
\hline Yes & $178(88.1)$ & $67(84.8)$ & $54(66.7)$ & $38(69.1)$ & \\
\hline No & $24(11.9)$ & $12(15.2)$ & $27(33.3)$ & $17(30.9)$ & \\
\hline Experience with W\&W in clinical practice & & & & & $<0.001$ \\
\hline Yes & $160(79.2)$ & $34(43.0)$ & $40(49.4)$ & $39(70.9)$ & \\
\hline No & $42(20.8)$ & $45(57.0)$ & $41(50.6)$ & $16(29.1)$ & \\
\hline Informed consent in case of clinical CR & & & & & $<0.001$ \\
\hline Yes & $174(86.1)$ & $48(60.8)$ & $55(67.9)$ & $46(83.6)$ & \\
\hline No & $28(13.9)$ & $31(39.2)$ & $26(32.1)$ & $9(16.4)$ & \\
\hline Preferred option in clinical CR & & & & & 0.531 \\
\hline Legal issue & $7(3.5)$ & $1(1.3)$ & $9(11.1)$ & $0(0)$ & 0.580 \\
\hline Lack of radiotherapy facility & $2(1.0)$ & $3(3.8)$ & $0(0)$ & $0(0)$ & 0.445 \\
\hline Patient refusal & $3(1.5)$ & $1(1.3)$ & $0(0)$ & $3(5.5)$ & 0.269 \\
\hline Plan for W\&W in the future & & & & & $<0.001$ \\
\hline Yes & $1(0.5)$ & $38(48.1)$ & $24(39.4)$ & $8(14.5)$ & \\
\hline No & $2(1.0)$ & $7(8.9)$ & $17(21.0)$ & $6(10.9)$ & \\
\hline NA & $199(98.5)$ & $34(43.0)$ & $40(49.4)$ & $41(74.5)$ & \\
\hline \multicolumn{6}{|l|}{ Restaging methods (multiple) } \\
\hline СT & 69 (34.2) & 72 (91.1) & $67(82.7)$ & $33(60.0)$ & $<0.001$ \\
\hline MRI & $196(97.0)$ & 70 (88.6) & $76(93.8)$ & $52(94.5)$ & 0.274 \\
\hline Sigmoidoscopy & $122(60.4)$ & $68(86.1)$ & $65(80.2)$ & $38(69.1)$ & $<0.001$ \\
\hline PET-CT & $41(20.3)$ & $43(54.4)$ & $5(6.2)$ & $25(45.5)$ & 0.089 \\
\hline Ultrasound & $12(5.9)$ & $7(8.9)$ & $13(16.0)$ & $6(9.1)$ & 0.061 \\
\hline Digital rectal examination & $9(4.5)$ & $2(2.5)$ & $4(4.9)$ & $4(7.3)$ & 0.455 \\
\hline
\end{tabular}




\section{$\begin{aligned} \text { Annals of } & \text { Current Status of "Wa } \\ \text { Coloproctology } & \text { Jung Wook Huh, et al. }\end{aligned}$}

Table 2. Continued

\begin{tabular}{|c|c|c|c|c|c|}
\hline Variable & China & Japan & Korea & Others & P-value \\
\hline Doses for radiation & & & & & 0.003 \\
\hline$<5,040$ cGy & $67(33.2)$ & $32(40.5)$ & $3(3.7)$ & $5(9.1)$ & \\
\hline 5,040 cGy & $89(44.1)$ & $32(40.5)$ & $68(84.0)$ & $33(60.0)$ & \\
\hline 5,400 cGy & $42(20.8)$ & $14(17.7)$ & $10(12.3)$ & $17(30.9)$ & \\
\hline$>5,040$ cGy & $4(2.0)$ & $1(1.3)$ & $0(0)$ & $0(0)$ & \\
\hline Chemotherapy regimen & & & & & $<0.001$ \\
\hline 5-Fluorouracil & $25(12.4)$ & $14(17.7)$ & $30(37.0)$ & $29(52.7)$ & \\
\hline Capecitabine & $137(67.8)$ & $33(41.8)$ & $43(53.1)$ & $19(34.5)$ & \\
\hline Oxaliplatin & $36(17.8)$ & $10(12.7)$ & $8(9.9)$ & $5(9.1)$ & \\
\hline Others & $4(2.0)$ & $22(27.8)$ & $0(0)$ & $2(3.6)$ & \\
\hline Chemotherapy during the resting period & & & & & $<0.001$ \\
\hline Same regimen of CRT & $90(44.6)$ & $19(24.1)$ & $11(13.6)$ & $7(12.7)$ & \\
\hline Different regimen of CRT & $36(17.8)$ & $7(8.9)$ & $10(12.3)$ & $7(12.7)$ & \\
\hline None & $76(37.6)$ & $53(67.1)$ & $60(74.1)$ & $41(74.5)$ & \\
\hline Interval between CRT and evaluation & & & & & 0.009 \\
\hline 4 Weeks & $42(30.7)$ & $17(21.5)$ & $15(18.5)$ & $8(14.5)$ & \\
\hline 6 Weeks & 59 (29.2) & $17(21.5)$ & $37(45.7)$ & $14(25.5)$ & \\
\hline 8 Weeks & $74(36.6)$ & $40(50.6)$ & $28(34.6)$ & $30(54.5)$ & \\
\hline 10 Weeks & $5(2.5)$ & $5(6.3)$ & $1(1.2)$ & $3(5.5)$ & \\
\hline 12 Weeks & $2(1.0)$ & $0(0)$ & $0(0)$ & $0(0)$ & \\
\hline$>12$ Weeks & $0(0)$ & $0(0)$ & $0(0)$ & $0(0)$ & \\
\hline Follow-up & & & & & 0.031 \\
\hline Every month & $60(29.7)$ & $4(5.1)$ & $8(9.9)$ & $2(3.6)$ & \\
\hline Every 2 months & 39 (19.3) & $16(20.3)$ & $14(17.3)$ & $6(10.9)$ & \\
\hline Every 3 months & $62(30.7)$ & $56(70.9)$ & $49(60.5)$ & $42(76.4)$ & \\
\hline Every 6 months & $0(0)$ & $1(1.3)$ & $4(4.9)$ & $2(3.6)$ & \\
\hline Others & $41(20.3)$ & $2(2.5)$ & $6(7.4)$ & $3(5.5)$ & \\
\hline Management for local regrowth & & & & & $<0.001$ \\
\hline Wait and follow-up & $3(1.5)$ & $0(0)$ & $0(0)$ & $0(0)$ & \\
\hline Radical surgery & $146(72.3)$ & $64(81.0)$ & 74 (91.4) & 49 (89.1) & \\
\hline Chemotherapy & $2(1.0)$ & $5(6.3)$ & $1(1.2)$ & $1(1.8)$ & \\
\hline Repeat CRT & $9(4.5)$ & $0(0)$ & $0(0)$ & $2(3.6)$ & \\
\hline Proton therapy & $0(0)$ & $0(0)$ & $0(0)$ & $0(0)$ & \\
\hline Local excision & $0(0)$ & $8(10.1)$ & $4(4.9)$ & $2(3.6)$ & \\
\hline Others & $42(20.8)$ & $2(2.5)$ & $2(2.5)$ & $1(1.8)$ & \\
\hline
\end{tabular}

Values are presented as number (\%).

W\&W, watch-and-wait; CRT, chemoradiotherapy; CR, complete response; CT, computed tomography; MRI, magnetic resonance imaging; PET-CT, positron emission tomography-computed tomography; NA, not applicable.

(ASCRS: $55 \%$ vs. non-ASCRS: $83 \%$ ).

Here, we present results of an international survey about W\&W in patients who achieved cCR after nCRT in Asia-Pacific countries. We found high support for the W\&W approach among surgeons in the APFCP. Eighty percent of responders supported the $\mathrm{W} \& \mathrm{~W}$ strategy, and $65.5 \%$ of responders used such a strategy for cCR after nCRT. This is the first international survey on contemporary views of the $\mathrm{W} \& \mathrm{~W}$ approach in Asia-Pacific countries. The low response rate is the major limitation to our study. Re- sponse bias, as well as the unequal distribution of participants with up to $48 \%$ of replies from China, could have potentially influenced our results. However, we received over 400 replies, over $97 \%$ of which were from colorectal surgeons and over $90 \%$ were from a university or tertiary hospital. This critical mass indicates the validity of the results and provides a general overview about the use of the W\&W strategy in clinical practice in Asia-Pacific countries and also presents opinions regarding several critical issues.

In conclusion, our survey provides current views of a W\&W ap- 
proach for patients who achieved clinical complete response after nCRT among specialized surgeons in Asia-Pacific countries. Our analysis suggests high support for the W\&W strategy in clinical practice in our area. These results will be useful for designing future prospective clinical trials in Asia-Pacific countries.

\section{CONFLICT OF INTEREST}

No potential conflict of interest relevant to this article was reported.

\section{ACKNOWLEDGMENTS}

The authors thank the MediOffice and Dr. Xiaolong Ma for collecting survey data.

\section{REFERENCES}

1. Sauer R, Liersch T, Merkel S, Fietkau R, Hohenberger W, Hess C, et al. Preoperative versus postoperative chemoradiotherapy for locally advanced rectal cancer: results of the German CAO/ARO/ AIO-94 randomized phase III trial after a median follow-up of 11 years. J Clin Oncol 2012;30:1926-33.

2. van Gijn W, Marijnen CA, Nagtegaal ID, Kranenbarg EM, Putter $\mathrm{H}$, Wiggers T, et al. Preoperative radiotherapy combined with total mesorectal excision for resectable rectal cancer: 12-year follow-up of the multicentre, randomised controlled TME trial. Lancet Oncol 2011;12:575-82.

3. Juul T, Ahlberg M, Biondo S, Espin E, Jimenez LM, Matzel KE, et al. Low anterior resection syndrome and quality of life: an international multicenter study. Dis Colon Rectum 2014;57:585-91.

4. Paun BC, Cassie S, MacLean AR, Dixon E, Buie WD. Postoperative complications following surgery for rectal cancer. Ann Surg 2010;251:807-18.

5. Dossa F, Chesney TR, Acuna SA, Baxter NN. A watch-and-wait approach for locally advanced rectal cancer after a clinical complete response following neoadjuvant chemoradiation: a systematic review and meta-analysis. Lancet Gastroenterol Hepatol 2017;2:501-13.
6. Appelt AL, Pløen J, Harling H, Jensen FS, Jensen LH, Jørgensen JC, et al. High-dose chemoradiotherapy and watchful waiting for distal rectal cancer: a prospective observational study. Lancet Oncol 2015;16:919-27.

7. Habr-Gama A, Gama-Rodrigues J, São Julião GP, Proscurshim I, Sabbagh C, Lynn PB, et al. Local recurrence after complete clinical response and watch and wait in rectal cancer after neoadjuvant chemoradiation: impact of salvage therapy on local disease control. Int J Radiat Oncol Biol Phys 2014;88:822-8.

8. Hendren SK, O’Connor BI, Liu M, Asano T, Cohen Z, Swallow CJ, et al. Prevalence of male and female sexual dysfunction is high following surgery for rectal cancer. Ann Surg 2005;242:212-23.

9. van der Valk MJM, Hilling DE, Bastiaannet E, Meershoek-Klein Kranenbarg E, Beets GL, Figueiredo NL, et al. Long-term outcomes of clinical complete responders after neoadjuvant treatment for rectal cancer in the International Watch \& Wait Database (IWWD): an international multicentre registry study. Lancet 2018;391:2537-45.

10. Renehan AG, Malcomson L, Emsley R, Gollins S, Maw A, Myint AS, et al. Watch-and-wait approach versus surgical resection after chemoradiotherapy for patients with rectal cancer (the OnCoRe project): a propensity-score matched cohort analysis. Lancet Oncol 2016;17:174-83.

11. Habr-Gama A, Perez RO, São Julião GP, Proscurshim I, Nahas SC, Gama-Rodrigues J. Factors affecting management decisions in rectal cancer in clinical practice: results from a national survey. Tech Coloproctol 2011;15:45-51.

12. Wynn GR, Bhasin N, Macklin CP, George ML. Complete clinical response to neoadjuvant chemoradiotherapy in patients with rectal cancer: opinions of British and Irish specialists. Colorectal Dis 2010;12:327-33.

13. Parmar KL, Malcomson L, Renehan AG. Watch and wait or surgery for clinical complete response in rectal cancer: a need to study both sides. Colorectal Dis 2019 Nov 21 [Epub]. https://doi. org/10.1111/codi.14912.

14. Schwartzberg DM, Grieco MJ, Timen M, Grucela AL, Bernstein MA, Wexner SD. Is the whole world watching and waiting? An International Questionnaire on the current practices of 'Watch \& Wait' rectal cancer treatment. Colorectal Dis 2018;20:1069. 


\section{$\begin{aligned} & \text { Colopnals of } \text { Current Status of "Wactology } \\ & \text { Jung Wook Huh, et al. }\end{aligned}$}

Appendix. Questionnaire (Current Status of Watch-and-Wait Policy for Irradiated Rectal Cancer in Asia-Pacific Countries 2019 by APFCP)

Nationality:

Age: $\square$ 30-39 $\square$ 40-49 $\square$ 50-59 $\square$ 60-69 $\square>70$

Colorectal Surgeon: $\square$ Yes $\square$ No

Affiliation: $\square$ University or Tertiary Hospital $\square$ Others

Hospital has a Department of Radiation Oncology: $\square$ Yes $\square$ No

Please tick each statement that you agree with:

1. Have you accepted the watch-and-wait policy?

$\square$ Yes $\square$ No

2. Have you performed the watch-and-wait policy in clinical practice?

$\square$ Yes $\square$ No

3. Have you explained the watch-and-wait option to your patient, if the patients who have received preoperative chemoradiotherapy (CRT) have a clinical complete response (CR)?

$\square$ Yes $\square$ No

4. What is your preferred option in patients with clinically CR?

$\square$ Watch-and-wait, always

$\square$ Watch-and-wait, selectively (old age, poor general condition, etc.)

$\square$ Radical surgery

5. (If you select 'No' in Question. 2) Why do you not perform the watch-and-wait policy in current practice? (check all)

$\square$ Inaccuracy of the evaluation method (imaging study)

$\square$ Lack of the evidence supporting the policy

$\square$ Personal memory of failure the treatment

$\square$ Legal issue

$\square$ Lack of radiotherapy facility

$\square$ Others:

6. (If you select 'No' in Question. 2) Do you plan to perform the watch-and-wait in future?

$\square$ Yes $\square$ No

7. Which methods do you perform for restaging? (check all)

$\square \mathrm{CT}$

$\square \mathrm{MRI}$

$\square$ Ultrasound

$\square$ Sigmoidoscopy (with biopsy)

$\square$ PET-CT

$\square$ Others:

8. How many doses do you use for the CRT?

$\square$ Less than 5,040 cGy

$\square 5,040 \mathrm{cGy}$

$\square$ 5,400 cGy

$\square$ More than 5,400 cGy 
9. Which chemotherapy regimen do you perform mostly?

$\square$ - $\mathrm{FU}$

$\square$ Capecitabine

$\square$ Oxaliplatin

$\square$ Others:

10. Do you use the chemotherapy in the resting period (the period between completion of CRT and the operation)?

$\square$ Yes $\square$ No

11. If you do (If you select 'Yes' in Question. 10), which regimen do you perform?

$\square$ Same regimen of CRT

$\square$ Different regimen of CRT

$\square$ Others:

12. When do you evaluate the CRT response after finishing the CRT?

$\square 4$ Weeks

$\square 6$ Weeks

$\square 8$ Weeks

$\square 10$ Weeks

$\square 12$ Weeks

$\square$ More than 12 weeks

13. After you perform a watch-and-wait, how often do you follow up?

$\square$ Every 1 months

$\square$ Every 2 months

$\square$ Every 3 months

$\square$ Every 6 months

$\square$ Others:

14. If you find a local regrowth in the patient who did a watch-and-wait, which management is preferred in your practice?

$\square$ Just wait and follow-up

$\square$ Radical surgery

$\square$ Chemotherapy

$\square$ Re-do CRT

$\square$ Proton therapy

$\square$ Local excision

$\square$ Others: 